ENTREVISTA

Rev Chil Salud Pública 2014;

Vol 18 (1): 95-99

\section{Luc Delannoy, director del Instituto de Neuroartes, Tijuana, México}

Jana Stojanova

Coordinación Editorial Revista Chilena de Salud Pública jana.stojanova@gmail. com

TUILLANG YUING

Posdoctorando Instituto de Estudios Avanzados (IDEA) Universidad de Santiago tuillang@yahoo.com
Luc Delannoy nació en Bélgica, es filósofo de formación y actual director del Instituto de Neuroartes, una red internacional de artistas, filósofos, científicos y profesionales de la salud mental con sede en México, cuyo propósito es desarrollar programas formativos y preventivos de salud mental.

Una larga trayectoria como investigador y profesor invitado en varias universidades del mundo, lo han llevado a indagar profundamente en la mente y la conciencia humana. Se trata de un trabajo donde progresivamente ha ido tomando protagonismo el tema de la autonomía en pacientes que padecen trastornos neurológicos y mentales, principalmente Alzheimer. De este modo, Delannoy ha podido romper las barreras disciplinarias y combinar en un mismo paisaje los aportes de la neurología y la filosofía de la mente, con una perspectiva particular de la estética donde lo artístico tiene un rol vital.

\section{Tuillang Yuing: Cuéntenos un poco los motivos de su visita a Chile.}

LD: Viajé a Chile el año 2013 para ofrecer una serie de conferencias en distintas universidades del país. Inauguré el año académico en la Universidad de Chile, hice un taller de investigación docente en Universidad Arcis; la Universidad Alberto Hurtado y la Universidad de Concepción me invitaron a presentar mi libro Convergencias. En ese contexto fui invitado por el Dr. Adolfo Vera, de la Universidad de Valparaíso, para presentar uno de mis libros aquí en Valparaíso, de donde surgió la idea de volver este año, 2014. He vuelto entonces para hacer un curso de verano en el programa de posgrado de literatura hispánica en la Universidad de Concepción y un curso teórico-práctico sobre Neuroartes en el Hospital Psiquiátrico dependiente de la Facultad de Medicina de la misma universidad, con terapeutas, enfermeras, psiquiatras y profesionales de la salud.

\section{Jana Stojanova: Un curso tipo práctico...}

LD: Sí, la idea era explicar los fundamentos de Neuroartes, y explicar cómo estamos trabajando, principalmente en cuestiones de salud mental; es decir, la relación que pueda tener el arte con la formación, prevención y terapia de la salud mental. Esto fue en Concepción.

Aquí en Valparaíso se trata de un curso de introducción a Neuroartes, pero que Adolfo llamó Neuroestética para facilitar la comprensión del concepto. El curso fue un éxito. 
JS: ¿Es un curso dirigido a los estudiantes de filosofía?

LD: No necesariamente. El Dr. Vera armó un grupo bastante diverso y de muy alto nivel. Llegaron músicos, gente de literatura, psicólogos, gente de teatro. Estuvimos trabajando una breve introducción a Neuroartes, principalmente temas sobre la percepción humana con el eje puesto en el arte visual. Este es el primer paso de muchas actividades que vamos a realizar aquí en Chile.

TY: De seguro esto merece un desarrollo muy extendido, pero la noción de Neuroartes no está muy difundida, y me imagino que más de alguna vez ha tenido que explicarla, porque la parte "neuro" de la palabra suena a laboratorio, a una cuestión biomédica, lo que comúnmente contrasta con el vocablo "arte". Cuéntenos cómo llega a desarrollar esta noción.

LD: Tienen mucha razón cuando dicen que la palabra "neuro" nos remite a los laboratorios. De hecho hay un texto que tenemos, que es una introducción a Neuroartes que se llama "Un laboratorio de ideas". Ahora, la idea de Neuroartes como laboratorio de ideas alude a un laboratorio en la calle, en la sociedad. No es una serie de experimentos en un laboratorio, porque la vida es más que un laboratorio de universidad. Hay muchos experimentos que se hacen en un laboratorio que no se pueden reproducir en la calle; entonces efectivamente nosotros estamos haciendo un laboratorio de ideas, pero ideas que realmente se implementan en la vida cotidiana, en diferentes comunidades.

Ahora bien, la idea de Neuroartes surgió de una inquietud mía de hace muchos años, de la pregunta por la relación entre la percepción humana y el arte; ¿qué está pasando en el cerebro de alguien que padece de una parálisis cerebral profunda cuando está en presencia de música? De ahí surge la inquietud de buscar los sustratos biológicos de los procesos creativos tanto del artista como del público. Lo mismo a nivel de las llamadas 'enfermedades mentales', lo que de paso implica poner en duda el término de 'enfermedad mental'; repensar el mundo de la psiquiatría, es decir, pensar la psiquiatría y pensar la enfermedad mental por medio de las artes. Surgió así una serie de propuestas transdisciplinarias que levantan un puente entre filosofía, psicología, ciencia empírica y artes, con el afán de entender mejor las cuestiones de salud mental. Ahí surgió una serie de preguntas que implican una reinterpretación del conocimiento, de la sabiduría, de la enseñanza, de la salud y muchas otras cosas. Finalmente, se puede llegar a una propuesta de sociedad.

\section{JS: A mí me interesan en términos prácticos} dos cosas: primero, ¿cómo son los estudios que se realizan en su centro? ¿Con pacientes? En definitiva, ¿qué tipo de estudios hacen?

LD: Vivimos en un mundo que tiene la tendencia a querer cuantificar todo. Ahora bien, es tan grave el problema de la cuantificación que incluso hace dos años, llegó a México un grupo de científicos y filósofos ingleses, para enseñar a los mexicanos como cuantificar el bienestar. Entonces, nosotros estamos un poco inquietos, un poco como "¿qué onda con esto?”. Hay cosas que no se tienen que cuantificar, si no caemos de nuevo en la locura de Descartes que logró relativizar su subjetividad para demostrar la existencia de Dios. Nosotros estamos un poco al margen de todo eso, y entonces nosotros no cuantificamos. La forma de medición de nuestro programa es el diseño de mapas. Nosotros diseñamos mapas. Todos nuestros programas son mapas a través de los cuales vemos si un individuo puede llegar de un punto a otro. Si puede ser funcional, si puede ser autónomo, si puede vivir con dignidad. Esto nos permite ver por dónde va el individuo, en lugar de la medición de la ciencia dura. Neuroartes no opera usando el método llamado hipotético-deductivo; así, para muchos las propuestas de Neuroartes no son científicas. Adoptamos la metáfora del filósofo de la ciencia Ronald Giere. Neuroartes es como una serie de mapas: poner a prueba un mapa no significa verificar de forma arbitraria puntos al azar sino más bien ver si a individuos usando el mapa, les ayuda a llegar donde quieren llegar. Contestar 
preguntas cuantitativas sobre los efectos de las campañas de Neuroartes no requiere rastrear afirmaciones teóricas, sino una atención cuidadosa en la información recopilada. Los resultados de los programas de Neuroartes no son inmediatos ni tampoco canjeables. Lo fundamental es permanecer en el camino de la dignidad y pensar del humano.

JS: Como la pregunta por los indices de normal y no-normal...

LD: Nosotros no trabajamos así. Son procesos bastante lentos, pero personas independientes del Instituto de Neuroartes que están en el sector de la salud pública nos han dicho -y han dicho públicamente- que los programas de Neuroartes permiten -particularmente en personas de la tercer edad-, bajar las dosis de medicamentos, alcanzar cierta tranquilidad y estabilidad emocional, disminuir la cantidad de días de hospitalización. O sea, es algo así como un complemento que los médicos ven, y del cual se advierten sus resultados... De diferentes departamentos de geriatras nos preguntan "¿cómo lo están haciendo?”. Esto es, si se quiere, una forma de medición, pero no es una medición dura. Trabajamos sobre los procesos. Consideramos que la subjetividad no es algo que se pueda medir. Aquello no es nuestro fin, si bien son resultados concretos que observan terceros que son de la profesión médica dura. Para nosotros es una retroalimentación que nos ayuda, ya sea a hacer modificaciones a nuestros programas o bien a seguir la línea. Nos da mucho aliento.

TY: Claro, no va con el enfoque clínico tradicional, de superar metas, de asignar el proceso terapéutico únicamente al individuo, como si fuese solo el individuo 'el enfermo', etcétera. Me parece que hay un compromiso cultural mayor. Digamos que "lo médico", "lo anormal", "lo enfermo" son nociones que responden siempre a una red social que las permite, una red que me parece que aqui se pone en cuestión. Ya no sería un enfoque desde lo científico, sería un enfoque desde otro lado, desde el arte...
LD: Todo el programa de Neuroartes tiene fundamento filosófico. Nosotros consideramos que la filosofía es la base de todo y que se tiene que aplicar en la vida cotidiana; que la filosofía no es nada abstracto sino que es algo muy concreto. Dicho eso, pensamos que el trabajo que hacemos es tratar de apoyar al individuo para que desarrolle su propia subjetividad y no transformarlo en algo que no es. Esto para nosotros es fundamental. Consideramos que tenemos la responsabilidad de frenar la patologización de la naturaleza humana, y esto implica un compromiso para evitar que los laboratorios farmacéuticos sigan colonizando la subjetividad de los individuos. Entonces, hay también un compromiso social -y vamos a decir también político-, fuertísimo. Lo tenemos bien claro: hay que frenar la patologización de la naturaleza humana; no permitir que los laboratorios farmacéuticos sigan moldeando e invadiendo la subjetividad de los individuos de acuerdo a sus propios intereses económicos. Esto es para nosotros un compromiso fundamental.

De ahí que cuando hay departamentos enteros de hospitales en México que nos dicen: "hemos bajado la cantidad de medicina" o "las personas tienen comportamientos distintos”, pues nos parece que no estamos tan equivocados. Así surge la propuesta de un nuevo contrato social, porque el contrato social que tenemos desde siglo XVIII ha fracasado y entonces hay que buscar otras vías.

JS: La segunda parte de mi pregunta es, ¿cómo practican su meta los neuroartistas? ¿Cómo se forman y cómo es su profesionalización?

LD: Nosotros tenemos una propuesta académica, o mejor dicho para-académica, para no entrar en la "titulitis aguda". Tenemos una parte para-académica que es una serie de cursos, diplomados y seminarios inter-generacionales, porque tenemos gente de 20 a 70 años que viene a seguir los cursos. Ofrecemos también el diplomado Neuroartes y tercera edad. Contamos con una planta docente internacional, y trabajamos para sensibilizar a las personas acerca de la cuestión de la tercera edad. Dentro del diplomado se forman equipos de 
trabajo y cada equipo tiene que desarrollar unos proyectos en sus comunidades para que realmente haya una práctica inmediata de lo aprendido. Por ejemplo, el año pasado se logró hacer un mural donde un grupo de adultos mayores en silla de ruedas salió a la calle y se apoderó de una pared para hacer un mural. En el país de los murales y los muralistas, es la primera vez en la historia de México que un grupo de adultos mayores invaden la calle en silla de ruedas y hacen un mural.

Luego hemos logrado que un grupo de adultos mayores abra una empresa chiquita que vende productos agrícolas. En fin, es una forma de empoderamiento de los adultos mayores, quienes en su mayoría están abandonados por sus familias y tienen demencia o problemas motores que les impiden ser autónomos. Una señora que hizo algo de nutrición y ahora está haciendo conferencias de nutrición para explicar su experiencia. Son cosas que realmente impactan pues son formas de empoderar al adulto mayor para que tenga un papel activo en su comunidad, no solamente a nivel artístico sino político y social.

Otra parte son los talleres. Allí nosotros vamos hacia las comunidades de adultos mayores, y ahí va un tallerista y hace un taller dos o tres veces a la semana. Hay entonces una rotación por diferentes asilos; los asilos que aceptan recibirnos puesto que también hay lugares que no permiten la entrada porque hay abusos de todo tipo. Pues entonces, cuando es posible, tratamos de orientar a los directivos de los asilos para hacer la vida más amable para los adultos mayores.

Por ejemplo si alguien quiere hacer un taller, tiene que hacer y preparar una propuesta. Todos los talleristas tienen que capacitarse con nosotros -sobre filosofía en muchos casos-, entonces ayudamos a la persona a orientar su taller, la metodología y la preparación de taller. Luego, también hacemos regularmente reuniones de talleristas para compartir experiencias. Además trabajamos con adultos mayores en las cárceles.

TY: Me gustaría que nos contara brevemente sobre la relación de este trabajo con su interés por la música, especificamente con el latín jazz, que yo sé que ha trabajado largamente. ¿Qué nos puede decir sobre este vínculo?

LD: Tuve la fortuna de nacer en una familia donde había una abuela pianista. Digamos que ya estaba metido desde casi la cuna en la música. Ella me introdujo al piano. A mi padre le encantaba el jazz. En la casa mi madre siempre estaba escuchando música clásica. Entonces había una variedad de música en la familia. Cada uno tomaba su turno para escuchar música, eso era muy divertido.

Pero además tenía un vecino -un amigo mío- que tenía parálisis cerebral profunda. Cuando venía a casa con sus padres, él se quedaba en casa. Así creció un tipo de relación muy extraña con este muchacho, pues a veces no entendía: siempre me quedaba así como “¿estará escuchando la música como yo?”. Y bueno, durante la adolescencia empiezas a reflexionar sobre las preguntas que te hiciste de niño y esto empezó a generar también esta cuestión.

Pues bien, y con el jazz yo estaba metido desde hace muchos años. Desde la preadolescencia, y siempre me ha interesado la improvisación en el jazz...

TY: Claro, justamente, el jazz latino caracterizado por esto de "la descarga", de romper los patrones, por la posibilidad de que en una experiencia colectiva acontezca algo que no estaba escrito -como en la experiencia musical europea, occidental: pauteada, de partitura. En el jazz latino hay una cuestión más ritual, bay la incorporación de elementos con raíz afro que parecieran también poner en cuestión el parámetro musical académico.

LD: En efecto, el lado afro-latino es fundamental; introduciéndome en la improvisación, y empezando a hacer estudios de filosofía, de neurociencias, se advierte una relación estrecha entre el concepto de improvisación en el jazz -y en la música en general-, y el funcionamiento del cerebro. El cerebro improvisa -diríamos-, simula, selecciona, anticipa. Nosotros tenemos que improvisar de forma constante. Y por eso tenemos tanto miedo, por eso necesitamos tener tanta seguridad, por eso necesitamos a veces sistemas políti- 
cos represivos, porque tenemos miedo de la improvisación. Pero nuestro cerebro está en un estado de improvisación constante, y los sistemas políticos en general tratan de impedir esta función de improvisación del cerebro para encaminar a los individuos hacia metas ya preestablecidas.

Entonces, luchando por un lado para favorecer la improvisación musical-que es una metáfora perfecta de la improvisación cerebral-, que realmente va perfecto para luchar contra mi 'bête noire' que es la singularidad objetiva preexistente, una singularidad pública y compartida por todos. Pues va todo de la mano. Y todo parte de la música. Todo parte de la música y de la improvisación, de todos los riesgos que tienes que correr con la improvisación: la aventura que hay que vivir; desarrollar tu subjetividad en función de tus habilidades de improvisación. Y esto se consigue por medio de las técnicas que aprendes como músico, con el contacto con el otro, y tu subjetividad que se desarrolla con la improvisación. Se hace por medio del arte y ello permite mantener o desarrollar una salud mental equilibrada, empática. Entonces, el desarrollo de habilidades para improvisar es la prevención para tener una sociedad equilibrada, sostenible.

TY: Es una apuesta estética en contra de la "anestesia" que cotidianamente se trata de imponer como mejoría. La pastilla es eso: adormecer la sensibilidad, y al contrario, aqui justamente por medio de la estimulación se busca recuperar un poco la salud...

LD: Exactamente, todo está muy relacionado. Y la música, y el jazz en particular, es una metáfora perfecta de la habilidad que puede tener el humano de improvisar. Es esto lo que a nosotros nos interesa: los riesgos, que implican un acto de fe en el otro. No una fe divina sino la fe como un acto de riesgo, la fe es un acto de apertura al otro. Eso es lo que a nosotros nos importa.

TY: Me imagino que en el caso del jazz se trata también de un contexto cultural que tiene que ver con la discriminación racial y por tanto también con la liberación...
LD: Efectivamente, yo siempre he considerado el jazz como una música de resistencia. Esta resistencia la tenemos que encarnar nosotros. La resistencia es una forma de empoderamiento, una manifestación del empoderamiento que necesitamos todos.

Ahora vamos a empezar a trabajar con niños en el estado de Chiapas, que es un estado bastante pobre de México, donde hay mucha población indígena, y hay también adultos mayores. Trabajaremos con elementos culturales propios de sus vidas. Digo esto porque la terapia no es transformar a alguien en lo que no es, lo que usualmente pasa porque el terapeuta tiene sus expectativas, mide al individuo como un objeto, etcétera.

JS: ¿Qué lugar tiene el Instituto dentro de la salud pública en México?, porque parece que en este momento sigue como un experimento que depende de las comunidades que permiten su ingreso.

LD: Tenemos un financiamiento del gobierno. Trabajamos con fondos públicos. Con ese dinero pagamos a todas las personas que intervienen. Somos 24 personas trabajando. Como además es una fuente de trabajo, entonces, incorporamos artistas de diferentes disciplinas. $\mathrm{Y}$ el proyecto es abrir un instituto de Neuroartes en Chile. Creo que en septiembre tendremos los papeles en orden para constituir una ONG con trabajo en Santiago, Concepción y Valparaíso. Aquí vamos a constituir un grupo de trabajo orientado al desarrollo de actividades académicas por medio de la Universidad de Valparaíso. De hecho vamos a firmar un convenio de colaboración para el 2015. Inicialmente va a ser un diplomado pero también buscamos desarrollar actividades con adultos mayores. Creo que va a ser un poco distinto al programa de México, porque la idea es capturar las inquietudes locales.

La primera etapa aquí en Chile -la parte académica-, va a ser una forma de sensibilización. Pero la parte concreta sería el trabajo con adultos mayores en diferentes comunidades del país. 